\title{
Sistem Informasi Geografis Pasar Tradisional Berbasis Web di Wilayah Kabupaten Badung
}

\author{
I Gede G Sastrawan 1), I Nyoman Yudi Anggara Wijaya ${ }^{2)}$, I Gede Juliana Eka Putra ${ }^{3)}$ \\ 1)23) Sistem Informasi, STMIK Primakara \\ Jl. Tukad Badung No. 135, Renon, Kec. Denpasar Sel., Kota Denpasar \\ 1) gelgelsastrawan98@gmail.com
}

\begin{abstract}
Traditional markets are a place for sellers of basic necessities produced by small and medium scale economic actors. The need for information on traditional markets for the community in Badung Regency is a very important instrument considering the very limited information about traditional markets such as market location information, market commodities and other information that is beneficial to the community. Lack of complete information makes some traditional markets in Badung Regency not yet well known. By utilizing information technology such as web-based geographic information systems, it can provide complete traditional market information to the public who want to know the traditional markets that are in the vicinity. The existence of this geographic-based information system is expected to be one of the solutions for data processing and information on traditional markets in Badung Regency, namely by building a web-based Geographic Information System (GIS) where in the system there are also market information and important information relating to traditional markets in the Badung regency. The software development carried out in this study uses the Waterfall method. This method is also called the Classic Life Cycle method. Called the Waterfall method because the first stage must be passed and finished first to be able to proceed to the next stage.
\end{abstract}

Keywords- traditional markets, market locations, geographic information systems, waterfall methods.

Intisari- Pasar tradisional merupakan wadah bagi penjual produk-produk kebutuhan pokok yang dihasilkan oleh para pelaku ekonomi bersekala menengah kecil serta mikro. Kebutuhan informasi pasar tradisional bagi masyarakat di Kabupaten Badung merupakan intrumen yang sangat penting mengingat sangat minimnya informasi tentang pasar tradisional seperti informasi lokasi pasar, komoditas pasar dan informasi-informasi lainnya yang bermanfaat bagi masyarakat. Kurangnya informasi yang lengkap membuat beberapa pasar tradisional yang ada di Kabupaten Badung belum begitu dikenal. Dengan memanfaatan teknologi informasi seperti sistem informasi geografis berbasis web, dapat memberikan informasi pasar tradisional secara lengkap kepada masyarakat yang ingin mengetahui pasar tradisional yang ada di sekitarnya. Adanya sistem informasi berbasis geografis ini diharapkan menjadi salah satu solusi untuk pengolahan data dan infromasi pasar tradisional di kabupaten badung yaitu dengan membangun sebuah Sistem Informasi Geografis (SIG) berbasis web dimana dalam sistem tersebut selain terdapat informasi lokasi pasar juga informasiinformasi penting yang berkaitan dengan pasar tradisional yang ada di wilayah kabupaten badung. Pengembangan perangkat lunak yang dilakukan pada penelitian ini menggunakan metode Waterfall. Metode ini disebut juga metode Classic Life Cycle. Disebut metode Waterfall karena tahap yang pertama harus dilalui dan seleseaikan terlebih dahulu untuk dapat melanjutkan ke tahap selanjutnya.

Kata Kunci- pasar tradisional, lokasi pasar, sistem informasi geografis, metode waterfall.

\section{Pendahuluan}

Pasar tradisional merupakan wadah bagi penjual produkproduk kebutuhan pokok yang dihasilkan oleh para pelaku ekonomi bersekala menengah kecil serta mikro. Kebutuhan informasi pasar tradisional bagi masyarakat di Kabupaten Badung merupakan intrumen yang sangat penting mengingat sangat minimnya informasi tentang pasar tradisional seperti informasi lokasi pasar, komoditas pasar dan informasi-informasi lainnya yang bermanfaat bagi masyarakat. Kabupaten Badung kota yang memiliki komoditas pasar dan pariwisata yang sangat menjanjikan karena padatnya penduduk dan banyaknya kebutuhan masyarakat akan produk produk pasar serta menjadi salah satu daerah destinasi wisata pariwisata. Namun meskipun merupakan kota besar keberadaan pasar tradisional di Kabupaten Badung mulai tersisih. Menurut data tahun 2009 dari Perusahaan Daerah Pasar Kabupaten Badung jumlah pasar yang di kelolanya berjumlah 10 Pasar yang Tersebar di Wilayah Kabupaten Badung. Salah satu permasalahannya adalah letak lokasi pasar tradisional yang biasanya terletak di lokasi-lokasi terpencil sehingga susah untuk dicari. Selain itu pengumpulan dan penyimpanan data pasar tradisional yang dilakukan pemerintah masih bersifat manual yaitu dengan melakukan pendataan langsung ke lokasi dan penyimpanan data menggunakan document hardcopy sehingga menyita banyak tempat. 
Perkembangan teknologi informasi seperti yang kita ketahui saat ini sangat berkembang pesat. Akan sangat bermanfaat apabila pemerintah kabupaten badung bisa memanfaatkan teknologi infromasi yang ada saat ini untuk menunjang kebutuhan data dan informasi pasar tradisional di wilayah kabupaten badung. Apabila teknologi informasi bisa dimanfaatkan dengan baik dalam pengolahan data dan informasi pasar tradisional di kabupaten badung, data yang informasi yang diperoleh akan lebih valid, menghemat biaya dan tempat serta tidak terlalu banyak menyita waktu. Oleh karena latar belakang di atas dalam penelitian ini penulis memberikan solusi untuk pengolahan data dan infromasi pasar tradisional di kabupaten badung yaitu dengan membangun sebuah Sistem Informasi Geografis (SIG) berbasis web dimana dalam sistem tersebut selain terdapat informasi lokasi pasar juga informasi-informasi penting yang berkaitan dengan pasar tradisional yang ada di wilayah kabupaten badung. Dengan menggunakan GIS, akan sangat memudahkan pengembang, konsumen, pemerintah, atau pihak - pihak yang terkait bisa mengetahui dengan mudah kondisi serta data-data dari tempat, tampak bangunan, jalan, lingkungan, taman, lapangan olahraga bahkan bisa dengan mudah mengetahui kondisi tempat[1].

\section{TINJAUAN PUSTAKA}

\section{A. Pasar Tradisional}

Pasar Tradisional adalah Pasar yang dibangun dan dikelola oleh Pemerintah, Pemerintah Daerah, Badan Usaha Milik Negara dan Badan Usaha Milik Daerah termasuk kerjasama dengan swasta dengan tempat usaha berupa toko, kios, los dan tenda yang dimiliki atau dikelola oleh pedagang kecil, menengah, swadaya masyarakat atau koperasi dengan usaha, modal kecil dan dengan proses jual beli barangdagangan melalui tawar menawar [2].

\section{B. Sistem Informasi Geografis (Geografis Information Sistem)}

Sistem Informasi Geografis (Geografis Information Sistem) adalah sebuah sistem yang didesain untuk menangkap, memanipulasi, menganalisa, mengatur dan menampilkan seluruh jenis data geografis. Akronim GIS terkadang dipakai sebagai istilah untuk Geographical Informasi Science atau Geospatial Informasi studies yang merupakan ilmu studi atau pekerjaan yang berhubungan dengan Geographic Information Sistem [3]. Pada asalnya, data geografi hanya disajikan diatas peta dengan menggunakan simbol, garis, dan warna. Elemen-elemen geometri ini dideskripsikan di dalam legendanya, misalnya; garis hitam tebal untuk jalan utama, garis hitam tipis untuk jalan sekunder dan jalan-jalan berikutnya.selain itu, berbagai data juga dapat ditutupkan berdasarkan sistem koordinat yang sama. Akibatnya, sebuah peta menjadi media yang efektif baik sebagai alat presentasi maupun sebagai bank tempat penyimpanan data geografis [4].

\section{PHP (Personal Home Page)}

PHP (Personal Home Page) adalah suatu bahasa pemrograman yang digunakan untuk menerjemahkan baris kode program menjadi kode mesin yang dapat dimengerti oleh computer yang bersifat server-side yang dapat ditambahkan ke dalam HTML [5].

\section{D. $M y S Q L$}

MySQL merupakan suatu jenis database server yang sangat terkenal. MySQL termasuk jenis RDBMS (Relational Database Manajement System). MySQL mendukung bahasa pemrograman $\mathrm{PH}$, bahasa permintaan yang terstruktur, karena pada penggunaannya SQL memiliki berberapa aturan yang telah distandarkan oleh asosiasi yang bernama ANSI. MySQL merupakan RDBMS (Relational Database Management System) server. RDBMS adalah program yang memungkinkan pengguna database untuk membuat, mengelola, dan menggunakan data pada suatu model relational. Dengan demikian, tabel-tabel yang ada pada database memiliki relasi antara satu tabel dengan tabel lainnya [6].

\section{Metodologi}

Pengembangan perangkat lunak yang dilakukan pada penelitian ini menggunakan metode Waterfall. Metode ini disebut juga metode Classic Life Cycle. Disebut metode Waterfall karena tahap yang pertama harus dilalui dan seleseaikan terlebih dahulu untuk dapat melanjutkan ke tahap selanjutnya [7]. Adapun tahapan-tahapan dalam pengembangan sistem menggunakan metode waterfall adalah sebagai berikut:

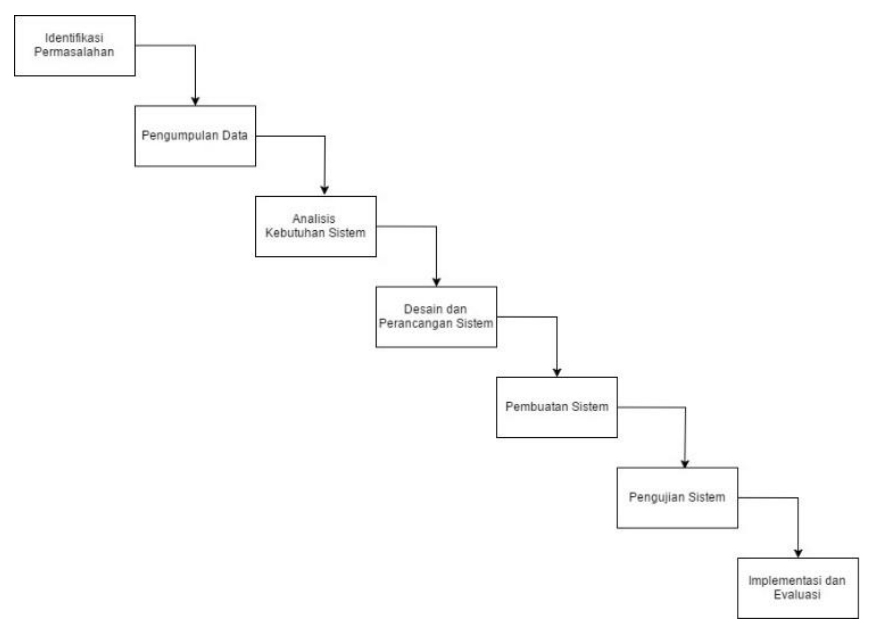

Gambar 1. Metode Waterfall

\section{HASIL PEMBAHASAN}

\section{A. Rancangan Penelitian}

Jenis Metode Penelitian yang dipiih adalah metode deskriptif. Metode Deskriptif adalah suatu metode yang berfungsi untuk mendeskripsikan atau memberi gambaran terhadap objek yag diteliti melalui data atau sampel yang telah terkumpul sebagaimana adanya (Fakta) [8]. Tahapan ini dilakukan sebuah perancangan sistem didasarkan atas hasil analisa kebutuhan yang telah dibahas sebelumnya. Perancangan sistem dirancang untuk mengetahui alur serta proses data yang terjadi di dalam sistem yang akan dibuat. Perancangan atau desain sistem terdiri dari beberapa bagian yaitu: Perancangan Data Flow Diagram (DFD) dan Entity Relationship Diagram (ERD). 


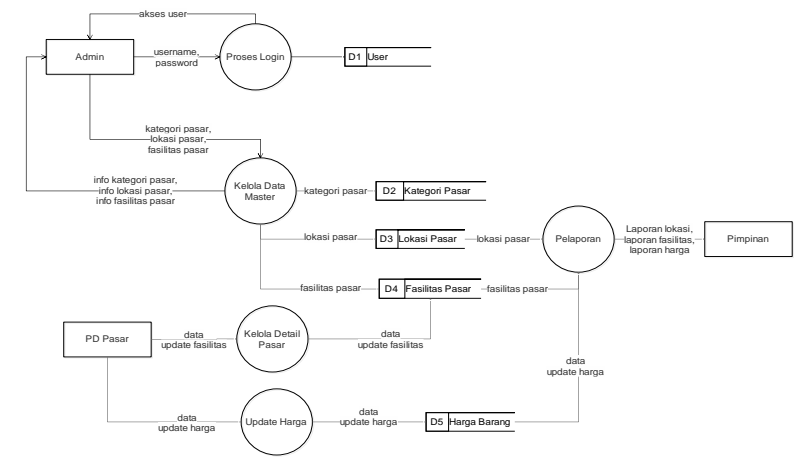

Gambar 2. Data Flow Diagram Level 0

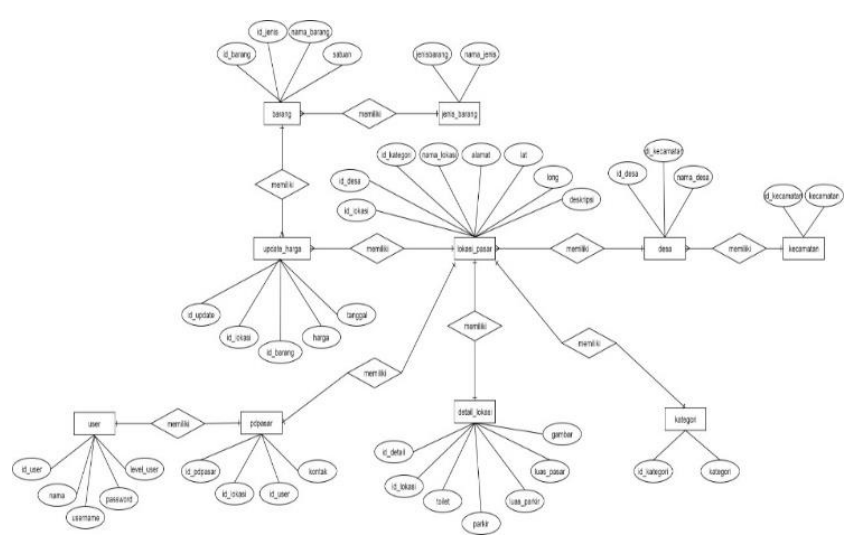

Gambar 3. Entity Realtion Diagram

\section{B. Implementasi Sistem}

\section{1) Halaman Login Admin}

Pada halaman Login terdapat beberapa komponen yaitu: input untuk memasukkan username dan password, serta tombol Login. Tampilan halaman Login dapat dilihat pada gambar 4

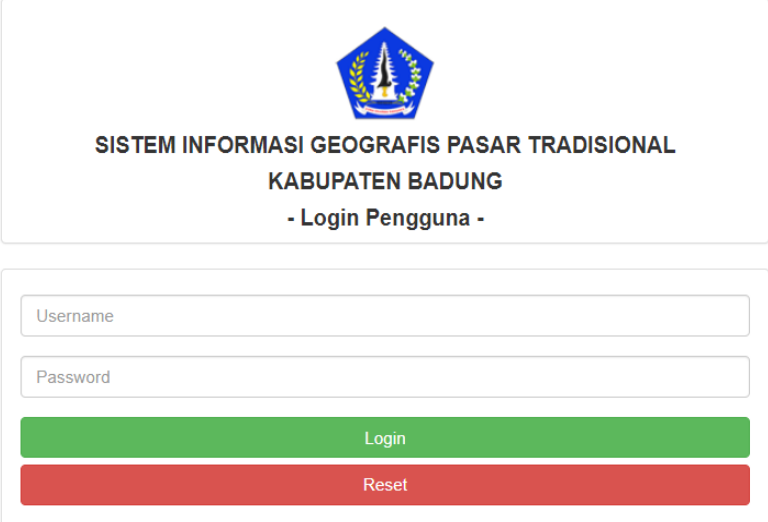

Gambar 4. Tampilan Halaman Login

\section{2) Halaman Home Website}

Pada halaman Home Website merupakan halaman pertama saat mengakses website sistem informasi geografis pasar tradisional kabupaten Badung. Tampilan halaman home dapat dilihat pada gambar 5 .

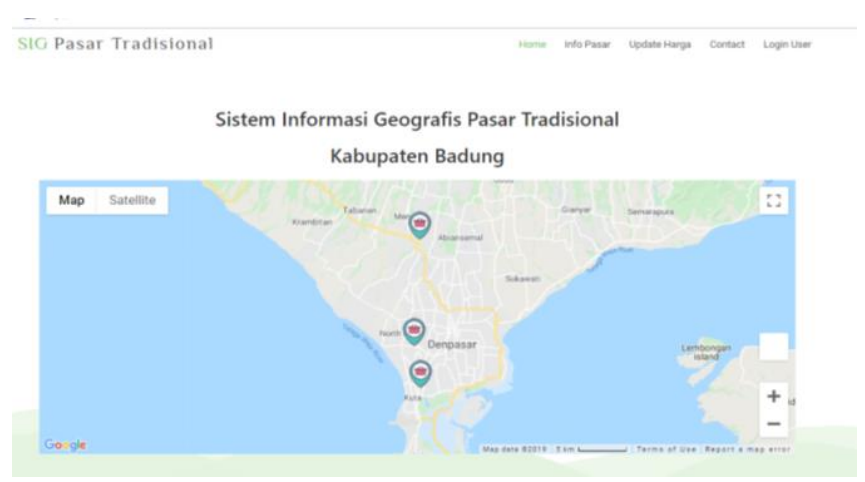

Gambar 5. Tampilan Halaman Home Website

\section{3) Halaman Info Pasar}

Pada halaman Info Pasar merupakan halaman untuk menampilkan info pasar tradisional di kabupaten Badung. Tampilan halaman info pasar dapat dilihat pada gambar 6 .

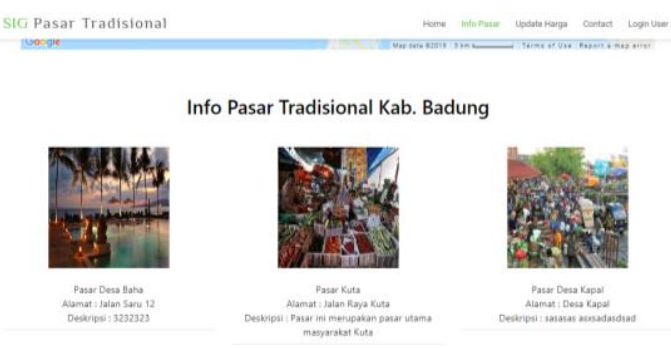

Gambar 6. Tampilan Halaman Info Pasar

4) Halaman Update Hatga Barang

Pada halaman Update Harga Barang merupakan halaman untuk menampilkan menampilkan update harga barang pasar. Tampilan halaman update harga barang dapat dilihat pada gambar 7 .

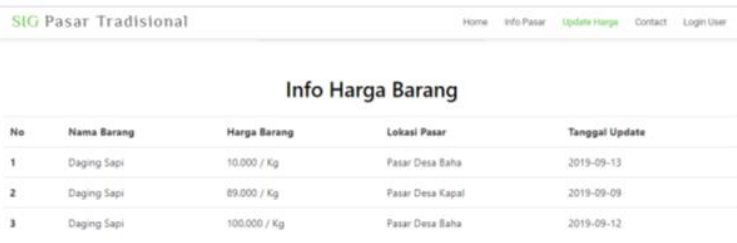

Gambar 7. Halaman Update Harga Barang

\section{5) Halaman Kontak}

Pada halaman kontak merupakan halaman untuk menampilkan informasi kontak. Tampilan halaman kontak dapat dilihat pada gambar 8 . 


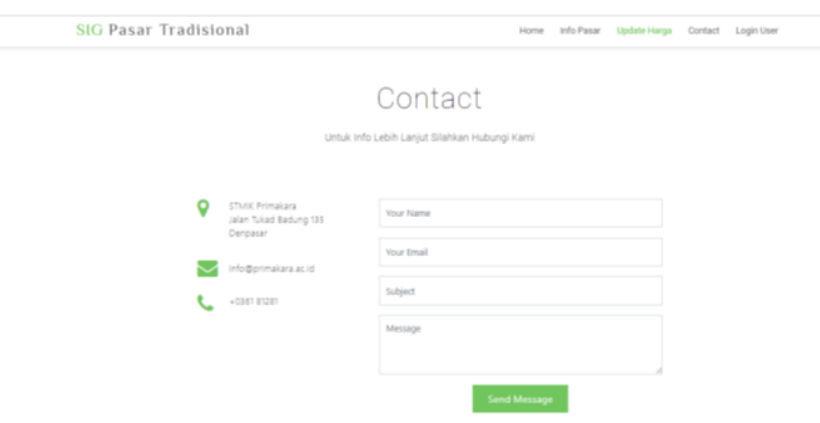

Gambar 8. Halaman Kontak

6) Halaman Laporan Grafik Harga Barang

Pada halaman ini menampilkan Laporan Grafik Harga Barang. Tampilan halaman Laporan Grafik Harga Barang dapat dilihat pada gambar 9.

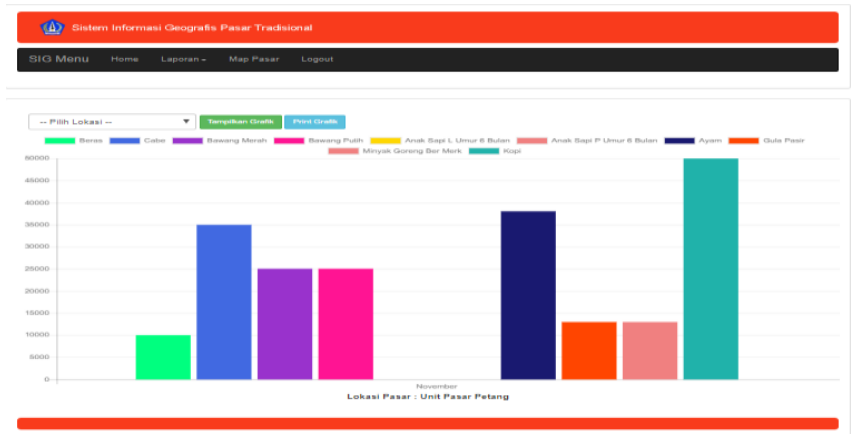

Gambar 9. Halaman Laporan Grafik Harga Barang

7) Halaman Laporan Fasilitas Pasar

Pada halaman ini menampilkan Laporan Fasilitas Pasar. Tampilan halaman Laporan Fasilitas Pasar dapat dilihat pada gambar 10 .
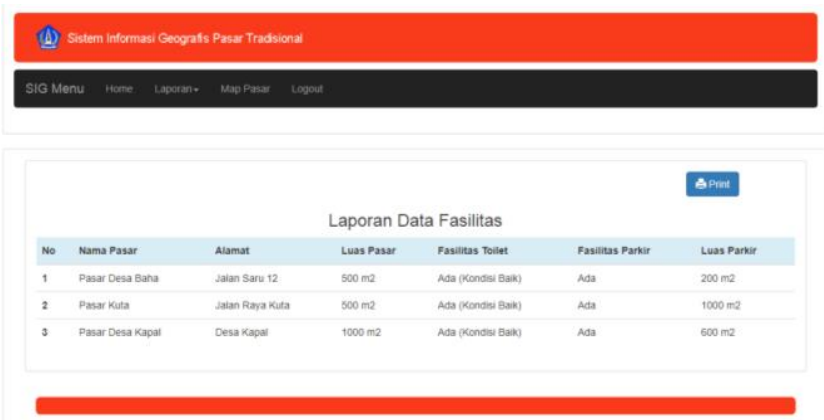

Gambar 10. Halaman Laporan Fasilitas Pasar

\section{Pengujian Sistem}

Pada tahapan ini dilakukan dengan metode wawancara kepada pengguna yang terlibat dalam sistem ini, yaitu admin dari Perusahaan Daerah Pasar Tradisional Kabupaten Badung dan Pengelola Pasar Tradisional. Dalam penelitian ini dilakukan wawancara kepada 5 pengguna/pemakai dari sistem informasi geografis pasar tradisional kabupaten Badung ini. Adapun beberapa kategori yang ditanyakan yaitu meliputi: design atau tampilan sistem, kemudahan dalam menggunakan sistem, dan informasi yang ditampilkan pada sistem ini.
Pada kategori design 4 orang responden dari pengguna menyatakan tampilan pada sistem ini sangat menarik. Sedangakan 1 orang responden menyatakan tampilan sistem ini cukup menarik.

Pada kategori kemudahan pemakaian sistem 2 orang responden dari pengguna menyatakan sistem ini sangat mudah untuk digunakan, selain itu 3 orang responden dari pengguna menyatakan cukup mudah untuk menggunakannya.

Berikutnya adalah pada kategori proses manajemen pasar pada sistem 3 orang responden pengguna menyatakan sistem ini sangat membantu mereka dalam proses manajemen pasar. Sedangkan 2 orang responden pengguna menyatakan cukup membantu mereka dalam proses manajemen pasar.

Sedangkan pada kategori informasi yang ditampilkan sistem ini, 3 orang responden pengguna menyatakan sistem ini mempermudah mereka dalam mendapatkan informasi tentang lokasi pasar dalam sistem ini, selebihnya 2 orang menyatakan cukup dipermudah dalam akses informasi.

Penjelasan diatas menunjukkan bahwa secara keseluruhan sistem informasi geografis pasar kabupaten Badung ini sudah baik. Namun beberapa pengguna mengharapkan agar fitur-fitur dari sistem ini lebih banyak lagi, seperti fitur untuk menampilkan jarak lokasi pasar dengan rumah. Selain itu pengguna lain juga memberi masukan supaya tersedia versi aplikasi mobile.

\section{KESIMPULAN}

Model Sistem Informasi Geografis Pasar Tradisional di wilayah kabupaten Badung yang di kembangkan ini layak diterapkan untuk memudahkan memanajemen pasar di wilayah kabupaten badung. Namun demikian, fitur - fitur seperti harga barang, parkir masih perlu di paparkan lebuh jauh, serta diintegrasikan pada teknologi terbaru, sehingga pengguna dapat mengaksesnya secara mobile.

\section{REFERENSI}

[1] I. G. J. E. P. Ida Bagus Kade Dwi Suta Negara, Ronny Susianto Susilo, "Sistem Informasi Geografis Monitoring Jalan Kabupaten Jembrana Berbasis Web," vol. 2, no. 2, pp. 271-279, 2015.

[2] Peraturan Presiden Republik Indonesia, Nomor 112 Tahun 2007 Tentang Penataan dan Pembinaan Pasar Tradisional, Pusat Perbelanjaan dan Toko Modern, BAB 1 Pasal 1.

[3] E. Irwansyah, Sistem Informasi Geografis: Prinsip Dasar dan Pengembangan Aplikasi, I. Yogyakarta: Digibooks, 2013.

[4] I. N. Yudi and A. Wijaya, "Perancangan SIG Untuk Monitoring Titik Api Pada Taman Nasional Bali Barat," pp. 146-154.

[5] Supono, Pemrograman Web dengan Menggunakan PHP dan Framework Codeigniter. Yogyakarta: Deeppublish, 2018.

[6] A. Kurniawan, Belajar Mudah Spss untuk Pemula. Yogyakarta: Mediakom, 2010.

[7] Muharto dan Arisandy Ambarita, Metode Penelitian Sistem Informasi. Yogyakarta: Deeppublish, 2016.

[8] Sugiyono, Metode Penelitian Kuantitatif, Kualitatif dan $R \& D$. Bandung: Alfabeta, 2009. 